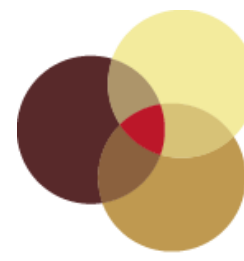

contennporaneity

Vol 7, No 1 (2018) ｜ＩSSN 2153-5914 (online) | DOI 10.5195/contemp/2018.245

http://contemporaneity.pitt.edu

\title{
Destruction and Solution
}

\author{
Meghan Kozal
}

\begin{abstract}
About the Artist
Meghan Kozal is an undergraduate at the University of Notre Dame, majoring in design and minoring in art history and computing and digital technologies. She is involved in various cultural clubs including the Asian American Association and the Filipino American Student Organization as well as several faith communities on campus. Her work has been exhibited in shows around the Toledo area, including the Northwest Ohio Community Art Exhibition as well as in South Bend at the Colfax Gallery and the Snite Museum of Art, and she looks forward to exhibiting a piece in Grand Rapids, Michigan's ArtPrize 10 at the Monroe Community Church. Her work has also been featured in The Juggler, a journal at the University of Notre Dame, and Polaris, a journal from Ohio Northern University. Meghan has been in the art and design field for years, working in local galleries and museums and doing graphic design work for many groups on campus. This coming year, she will be interning with Campus Ministry at the University of Notre Dame in communications and with the Notre Dame Institute for Global Investment as a designer and web developer. She hopes to pursue a master of fine arts degree after graduation, so as to continue on the path to becoming an arts educator.
\end{abstract}




\section{Destruction and Solution}

Art is made to challenge. In my work, I compose images that will confront viewers while also challenging me to see an issue differently. My work stems from a love of art history and a desire to present stories from the news in a new and intriguing way. In particular, I tend to focus on issues in the Middle East, an area of the world I have seen constantly covered in the media since my childhood, and attempt to give a new voice to pervasive problems. Education also plays a large role in my work, whether referred to directly or as a lens through which my work is composed. Education is a natural focus for me as it is a field that I have grown up surrounded by. Both of my parents are educators, and I hope also to pursue a job in that field. In combining all these areas of interest, I often use rather simple compositions with a regular presence of geometric shapes. I find that in breaking the ideas down to their essential elements, I am better able to convey a message and at the same time leave my work much more open, creating a space where viewers can place themselves and their experiences. This technique allows me to work with global issues in a wider capacity, linking issues to show how widespread they may appear and encouraging viewers to become actively involved in them no matter their viewing perspective. 


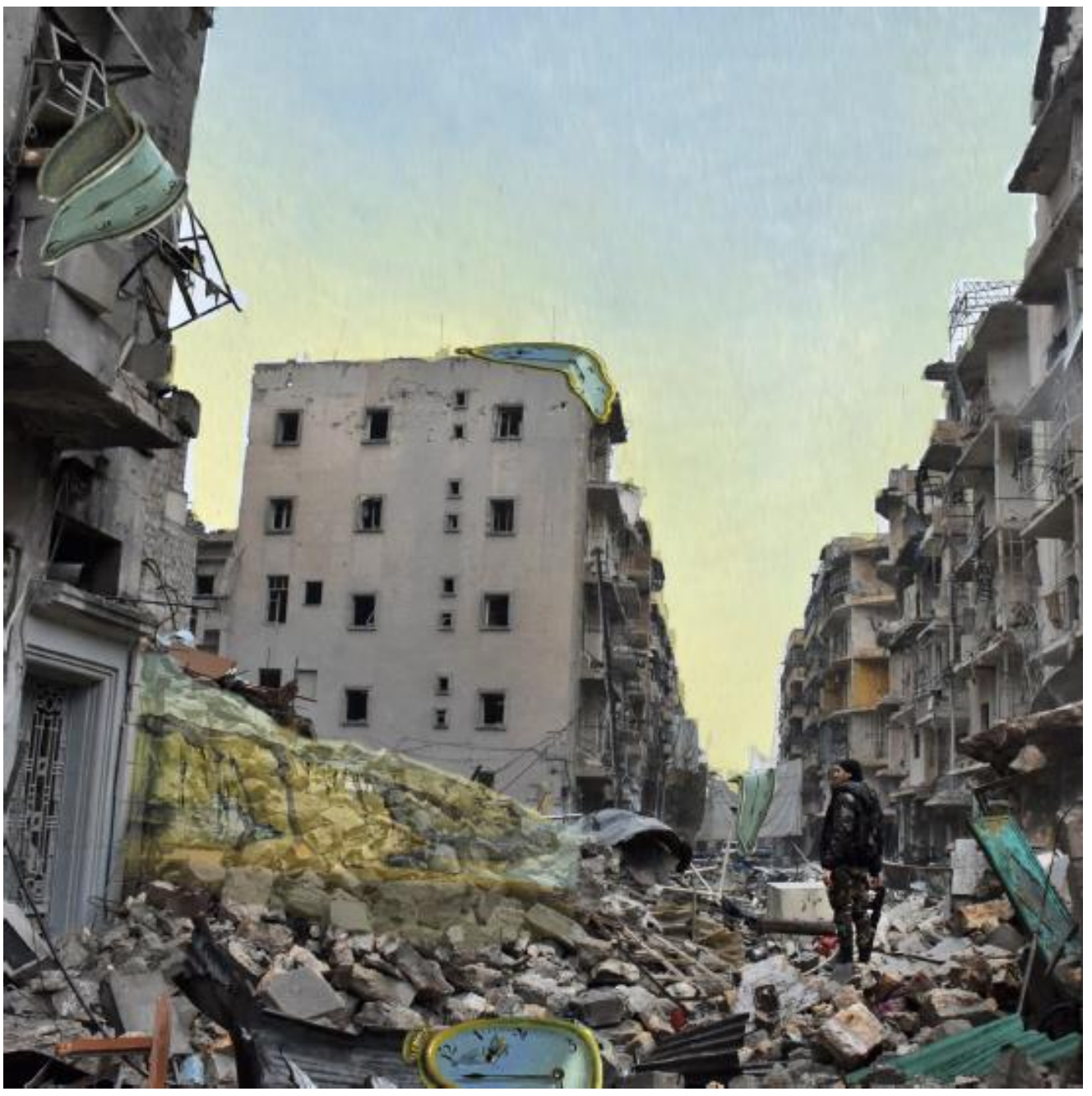

Figure 1

Meghan Kozal, Persistence of Memory, 2017, Graphic Design. 


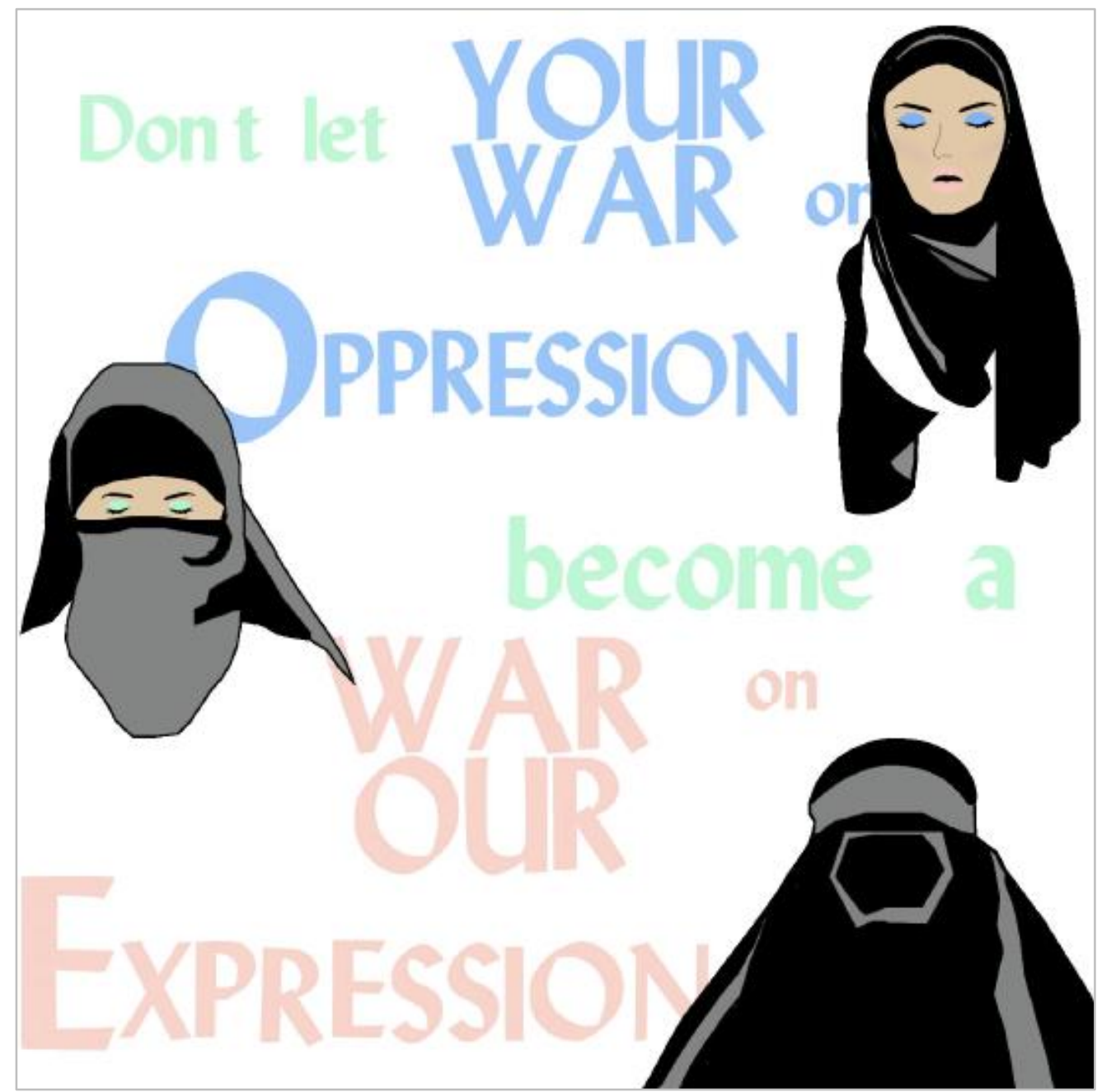

Figure 2

Megan Kozal, Expression/Oppression, 2017, Graphic Design. 


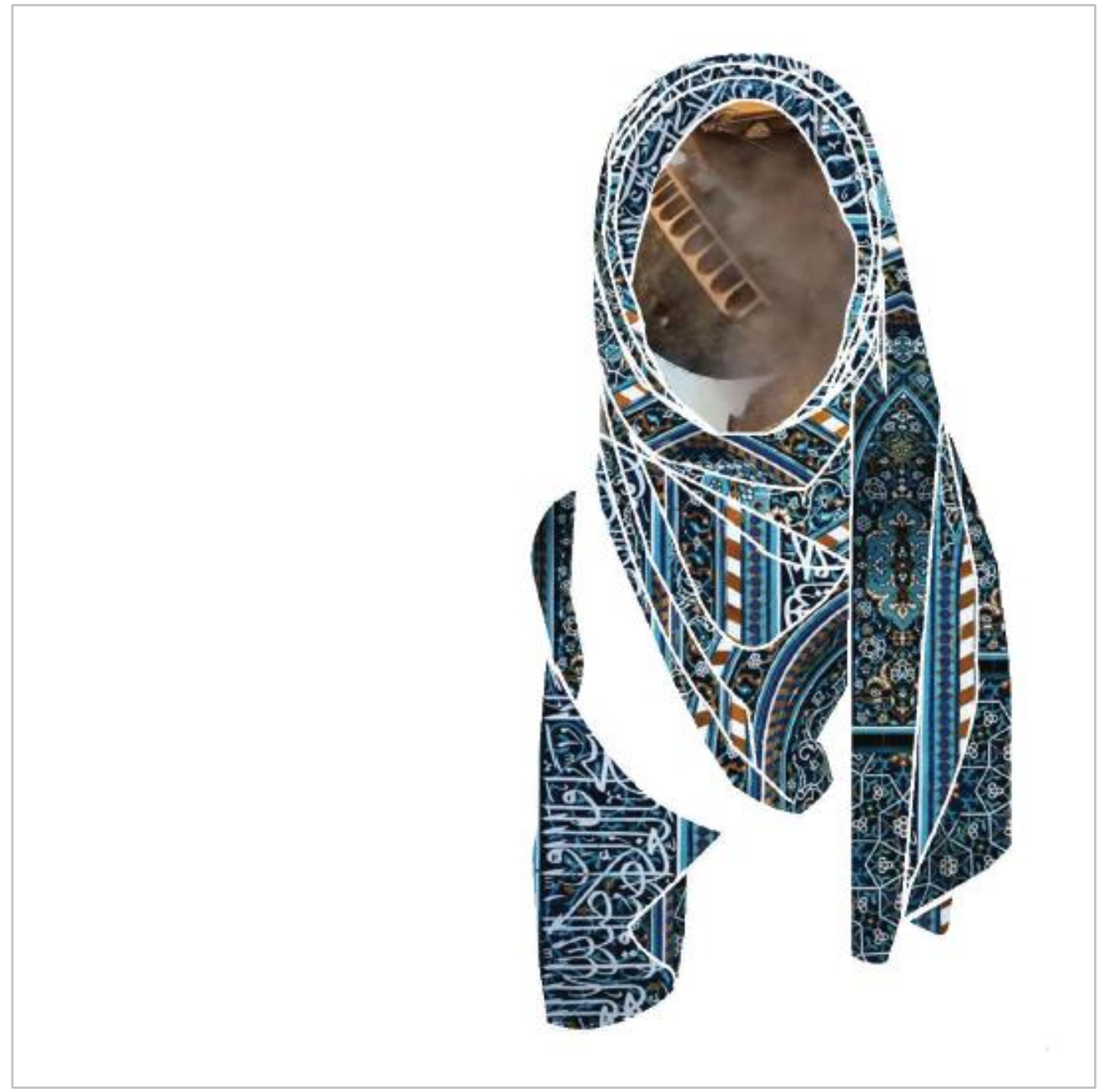

Figure 3

Meghan Kozal, Destruction, 2017, Graphic Design.

(c) $\mathbf{E Y}$ Attribution 4.0 United States License.

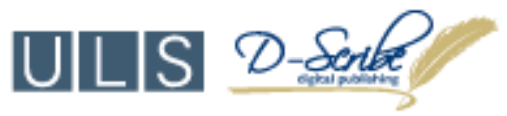

This journal is operated by the University Library System of the University of Pittsburgh as part of its D-Scribe Digital Publishing Program, and is co-sponsored by the University of Pittsburgh Press. 